Supporting Information

\title{
Noble metal nanoparticles in pectin matrix.
}

\section{Preparation, film formation, property analysis and application in electrocatalysis}

\author{
Joanna Dolinska $^{1 *}$, Marcin Holdynski ${ }^{1}$, Piotr Pieta ${ }^{1}$, Wojciech Lisowski ${ }^{1}$, Tomasz Ratajczyk ${ }^{1}$, \\ Barbara Palys ${ }^{2}$, Anna Jablonska ${ }^{2}$ and Marcin Opallo ${ }^{1 *}$ \\ ${ }^{1}$ Institute of Physical Chemistry, Polish Academy of Sciences, Kasprzaka 44/52, 01-224 \\ Warszawa, Poland
}

${ }^{2}$ Faculty of Chemistry, University of Warsaw, Pasteura 1, 02-093 Warszawa, Poland 


\section{S1 NMR materials characterization}

${ }^{13} \mathrm{C}$ NMR spectrum of the amidated-pectin from Pektowin-Jasło (Figure S1) reveals signals originating from pectin and sucrose added to the original product as standard in the food industry. The signals from sucrose were easily identified ${ }^{7}$.

NMR signals from $\mathrm{COOH}$ and $-\mathrm{CONH}_{2}$ functionalities of amidated pectin from these two groups are very diagnostic. Unfortunately, their ${ }^{1} \mathrm{H}$ NMR identification is limited because of the fast H/D exchange in water - a natural environment of these materials. On the other hand, weak and broadened ${ }^{13} \mathrm{C}$ NMR signals in the carbonyl region at 171.6 and $175 \mathrm{ppm}$ (red spectrum in Figure S1) can be assigned to $-\mathrm{CONH}_{2}$ and $-\mathrm{COOH}$ groups respectively ${ }^{8}$. Furthermore, weak signals related to $-\mathrm{CH}$ - units at $110-50 \mathrm{ppm}$ are also visible on the ${ }^{13} \mathrm{C}$ NMR spectra of Pektowin-Jasło pectin. All these signals are clearly seen in the same positions on ${ }^{13} \mathrm{C}$ NMR spectra of the reference pectin from Aldrich (black spectrum in Figure S1).

The comprehensive description of ${ }^{13} \mathrm{C}$ NMR spectra is not possible, due to their complex polymeric, highly heterogeneous and amorphous structure and partially overlapping with the resonances from the sucrose signals. NMR utilization to NMNPs/pectin materials is limited because of the low concentration of nanoparticles. The density of possible interactions between pectin and NPs is far beyond the NMR detection limit, even with the state of the art of NMR approaches. 


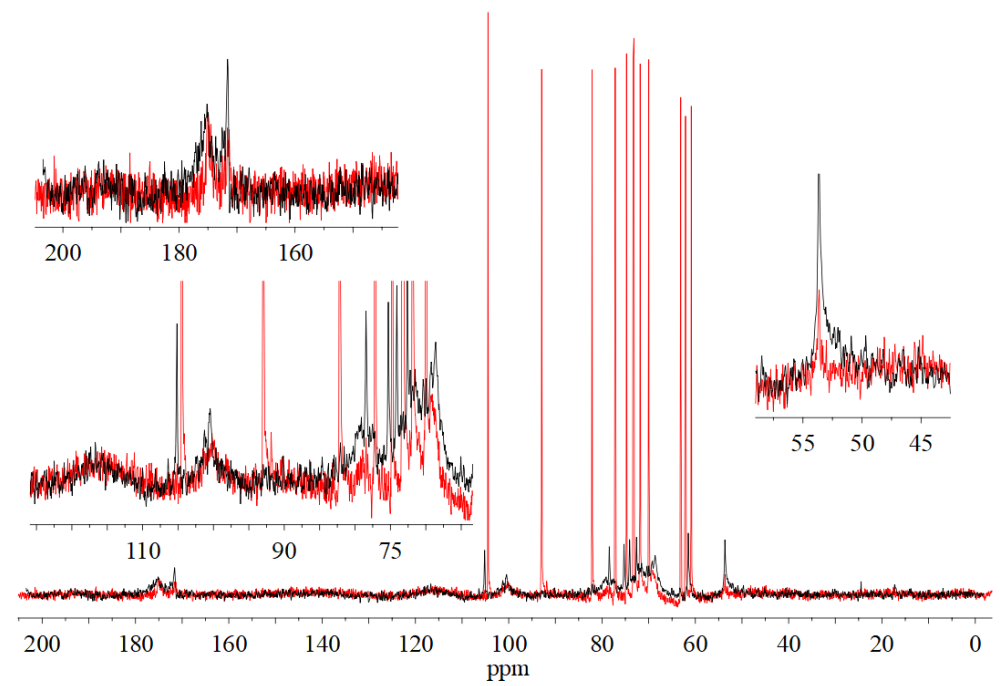

Figure S1A. ${ }^{13} \mathrm{C}$ NMR spectra of the amidated-pectin from Pektowin (red) and Aldrich (black).

We also made an attempt to characterize the studied material by estimating pectin to sucrose ratio. Unfortunately, the ${ }^{1} \mathrm{H}$ NMR spectrum indicates an excess of sucrose. This does not allow the precise evaluation of sucrose concentration via NMR. Copious washing out of sucrose with ethanol was not successful. Therefore, we propose another approach that can be straightforwardly used for the characterization of our system: the ratio of sucrose molecules to methylated rhamnose units of pectin. The ${ }^{1} \mathrm{H}$ NMR spectra (see Figure SI1B) revealed resonances at around $-1.2 \mathrm{ppm}$, attributed to the methyl (i.e., OMe) group of the pectin rhamnose unit ${ }^{9}$. Importantly, these signals are wellseparated from the other resonances and can be easily integrated and compared with the integral of the signal (also not overlapped) at 5.37, assigned to the anomeric proton from sucrose (and to the all anomeric protons from the pectin). Proceeding this way, we have obtained $I_{C H 3}=1$ and $I_{C H}=4.09$ and consequently, which means one sucrose molecule per twelve methylated rhamnose units. We are aware that the presented protocol is not entirely quantitative; however, it can be an asset for the pectin characterization methodology. 


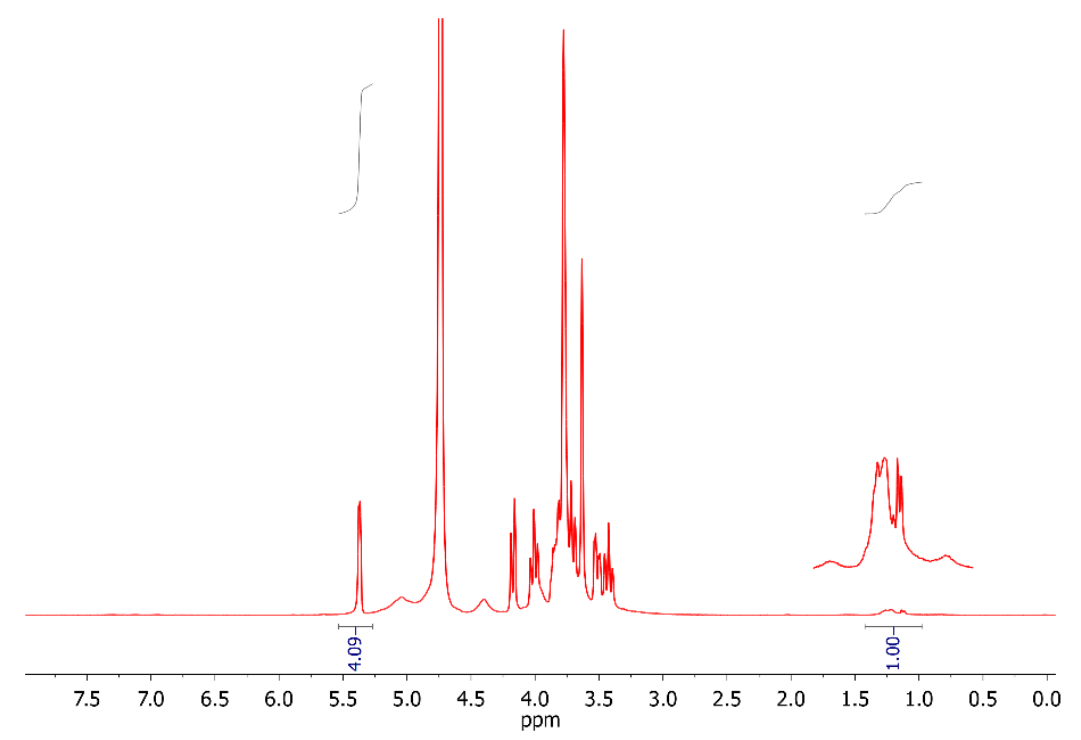

Figure S1B. ${ }^{1} \mathrm{H}$ NMR of the pectin.

The procedure of the sucrose/pectin molar ratio evaluations was as follows: the relaxation times $\mathrm{T}_{1}$ were evaluated for a few signals which are concerned with sucrose. Afterwards, the ${ }^{1} \mathrm{H}$ NMR multiscan spectra with $d 1=10 * \mathrm{~T}_{1}$ parameters were acquired. The $\mathrm{T}_{1}$ relaxation times of pectin are shorter than $\mathrm{T}_{1}$ for sucrose, as the first one is a complex polymer, and therefore the tumbling of this type of polymer is slower that the tumbling of the sucrose molecule. This allows us to record an integrable multi-scan ${ }^{1} \mathrm{H}$ NMR spectra. A baseline line and phase corrections of the ${ }^{1} \mathrm{H}$ NMR were carefully adjusted. Finally, the spectra were integrated. 


\section{S2 Synthesis}

(a)

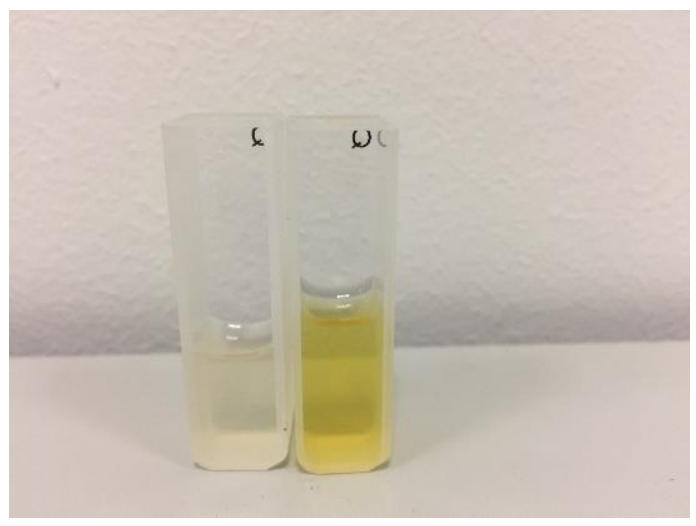

(b)

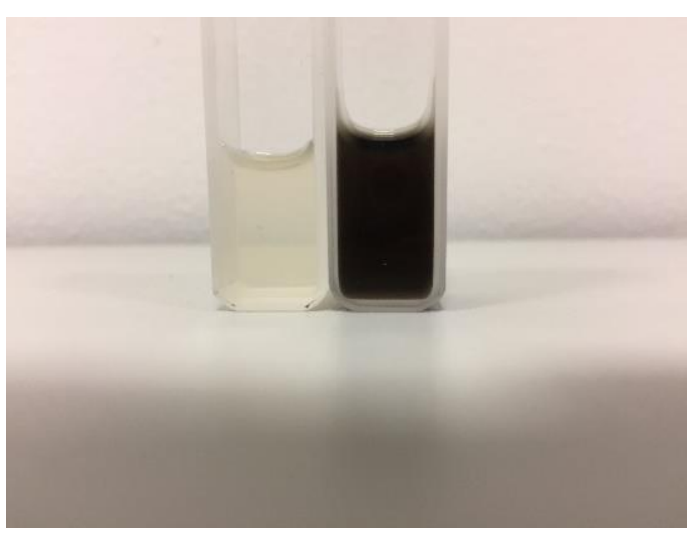

(b)

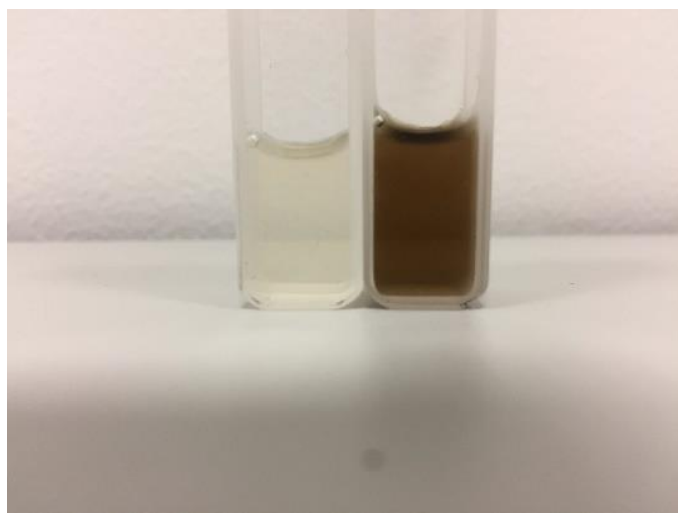

(d)

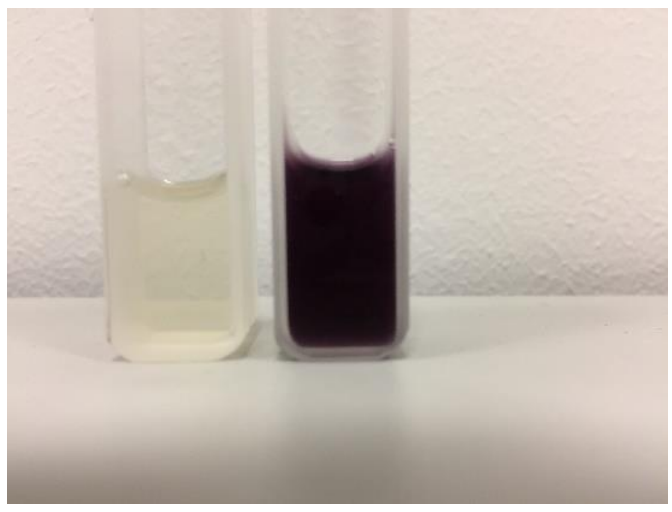

Figure S2. Cuvettes filled with pectin sol before and after addition of $\mathrm{Ag}(\mathrm{a}), \mathrm{Pd}$ (b), $\mathrm{Pt}$ (c) and $\mathrm{Au}$ (d) precursor. Three weeks passed after the addition of metal precursor. Photograph Courtesy of Joanna Dolinska. Copyright 2020. 


\section{S3 UV-vis spectroscopy}

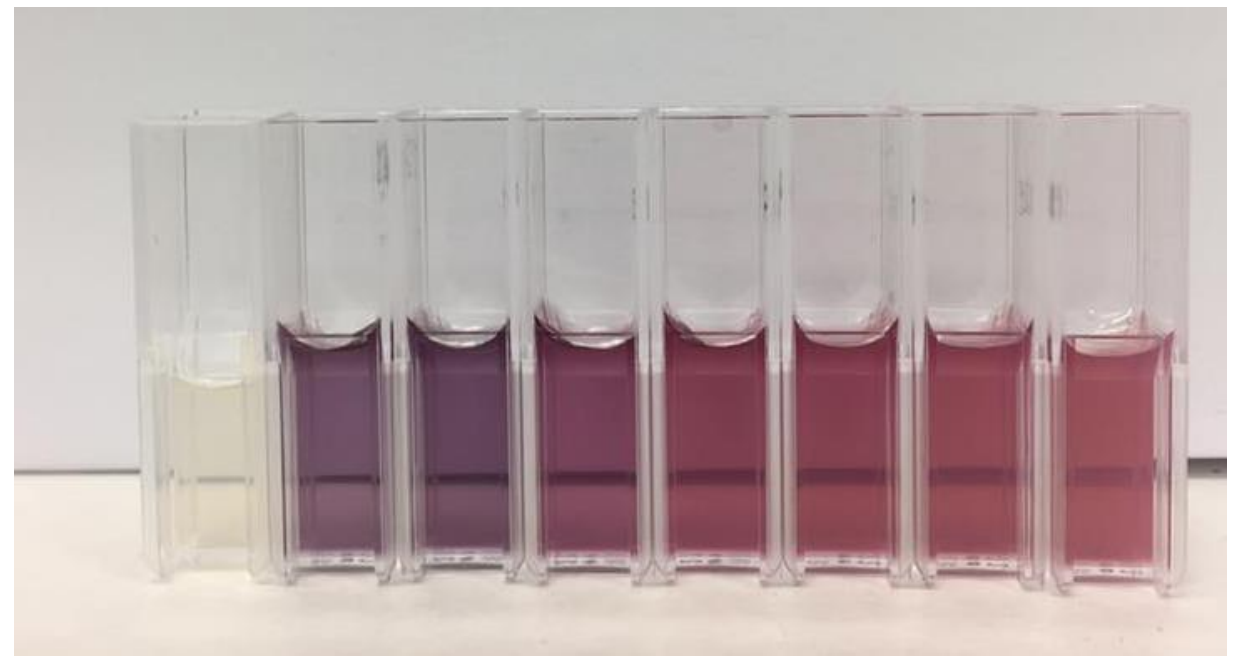

Figure S3. Cuvettes filled AuNPs/pectin sol prepared from $1 \mathrm{ml} 5 \mathrm{mM} \mathrm{HAuCl}_{4} \times 3 \mathrm{H}_{2} \mathrm{O}$ and 5 $\mathrm{ml} 0.15,0.25,0.35,0.45,0.55,0.65,0.75$ and $0.95 \mathrm{~g}$ (from left to right) $/ \mathrm{mL}$ solution. No precursor solution was added to the first cuvette on the left. Photograph Courtesy of Joanna Dolinska. Copyright 2020.

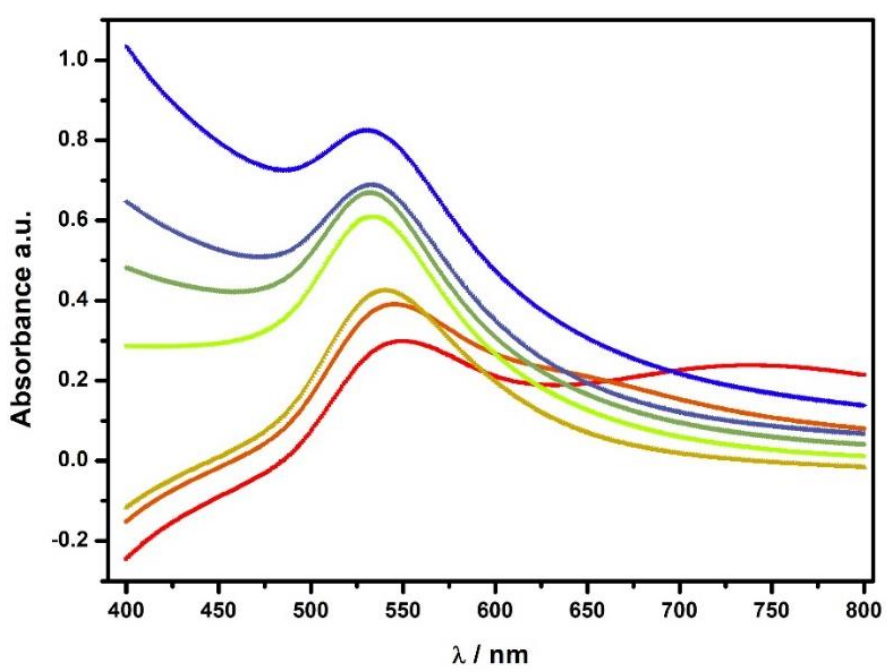

Figure S4. UV-vis spectra of AuNPs/pectin sol prepared from $1 \mathrm{ml}$ of $5 \mathrm{mM} \mathrm{HAuCl}_{4} \times 3 \mathrm{H}_{2} \mathrm{O}$ and $1 \mathrm{ml}$ of 0.15 (red), 0.25 (orange), 0.35 (yellow-green), 0.45 (light green), 0.55 (dark green), 0.75 (blue) and 0.95 (violet) $\mathrm{g} / \mathrm{mL}$ pectin solution. 


\section{S4 FTIR and Raman spectra}

The infrared spectrum of the amidated citrus pectin shows several differences compared to the non-amidated citrus pectin (Figure S5). The list of differences opens the sharp band at $3563 \mathrm{~cm}^{-1}$ due to the $\mathrm{O}-\mathrm{H}$ stretching mode of the non-hydrogen bonded $\mathrm{OH}$ groups of sucrose ${ }^{10}$. Other bands characteristic for sucrose are expected in the $900-1300 \mathrm{~cm}^{-1}$ range involving the contribution from the pyranose ring ${ }^{10}$. Due to the large similarity between sucrose and the galacturonic acid ring the detailed analysis of the $900-1300 \mathrm{~cm}^{-1}$ is very difficult. However, the three intense bands at 1069 , 990 and $909 \mathrm{~cm}^{-1}$ characteristic for sucrose ${ }^{10}$ are clearly visible in the concerned spectral range. The relatively high intensity of sucrose bands compared to the intensity of the carboxyl groups of the pectin suggests that the content of sucrose is high.

The commercially available citrus pectin shows an intense band at $3439 \mathrm{~cm}^{-1}$ due to the $\mathrm{O}-\mathrm{H}$ stretching mode of the hydrogen-bonded $\mathrm{OH}$ groups and possible traces of liquid water in the spectrum (Figure S5 a). The analogous band of the amidated pectin has a different spectral shape. The three spectral components at 3390,3338 and $3241 \mathrm{~cm}^{-1}$ are distinguishable, signifying the presence of secondary and primary amide group. The characteristic amide $\mathrm{I}$ band at $1670 \mathrm{~cm}^{-1}$ is observed only in the spectrum of the amidated pectin. The intensity of the amide I band is slightly higher than the neighbouring band at $1752 \mathrm{~cm}^{-1}$ due to ester groups suggesting that the number of amidated groups is higher than ester groups.

The bands at $1752 \mathrm{~cm}^{-1}$ and $1630 \mathrm{~cm}^{-1}$ correspond to the estrified and non-estrified pectin carboxylic groups respectively It was demonstrated that the intensity of the $1750 \mathrm{~cm}^{-1}$ band normalized to the sum of intensities of 1750 and $1630 \mathrm{~cm}^{-1}$ bands depends linearly on the degree 
of the esterification of a pectin sample ${ }^{11}$. Here the value of this parameter indicates that the degree of esterification is similar for both pectins, and it equals to c.a. $45 \%$.

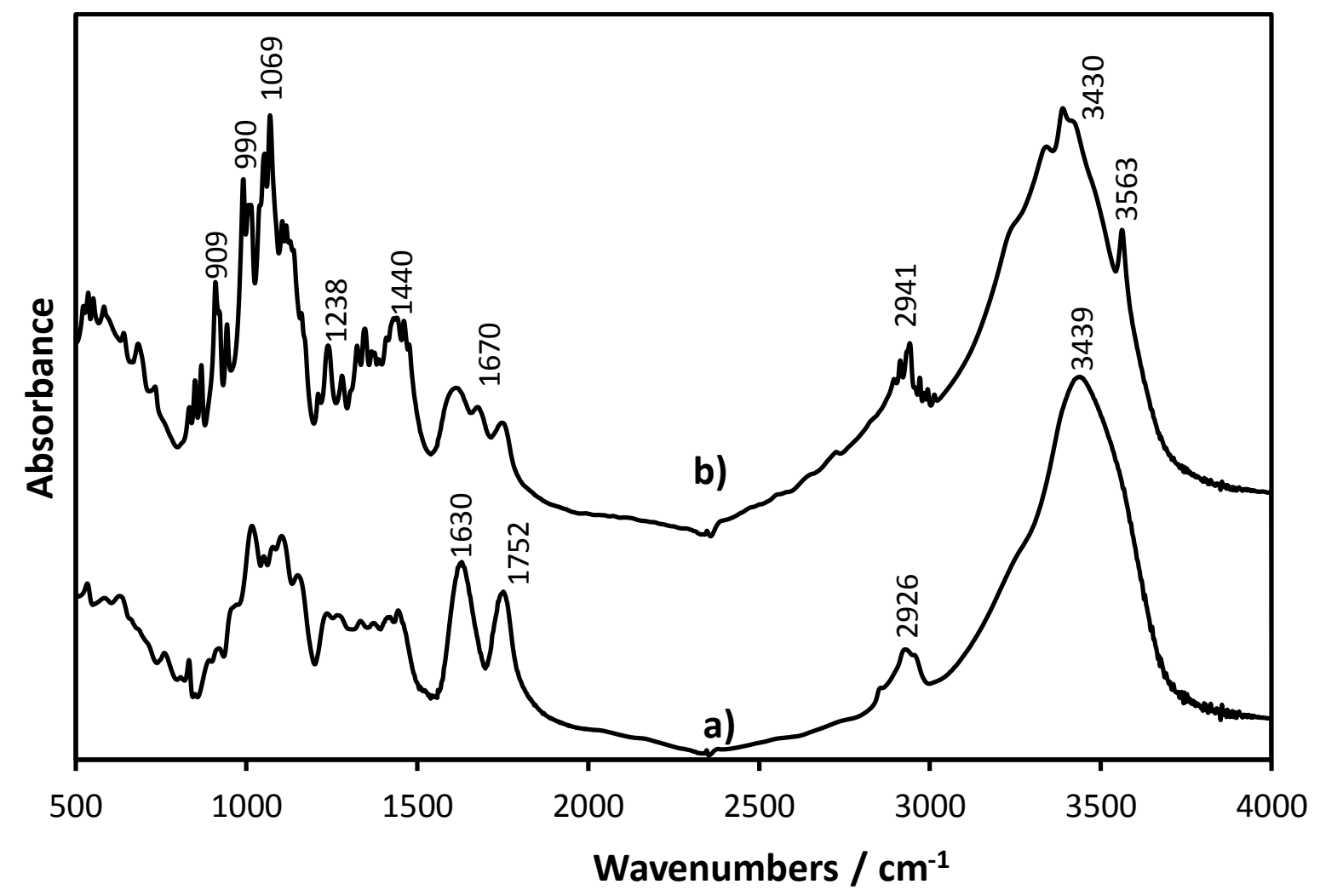

Figure S5. Comparison of the infrared spectra (in $\mathrm{KBr}$ pellet) of the commercially available citrus pectin (Sigma Aldrich) and the amidated citrus pectin

IR spectra of pectin gels were studied by the ATR technique. The IR spectrum of the amidated citrus pectin gel (Figure S6a) is dominated by very intense bands of liquid water at 3350 and 1640 $\mathrm{cm}^{-1}$. These bands overlap with the $\mathrm{OH}$ contribution of the pectin and many other typical bands. The most intense bands are observed at 1018, 1106, and $1149 \mathrm{~cm}^{-1}$ and are attributed to C-O-C atoms of glycoside and ester groups ${ }^{12,13}$. Other bands typical for pectin appear upon drying (Figure 2b) with C-O-C modes being most intense. In the range, $900-1200 \mathrm{~cm}^{-1}$ numerous overlapping bands are visible with the maximum at $1012 \mathrm{~cm}^{-1}$, while two well-separated 1106 and $1149 \mathrm{~cm}^{-1}$ 
components are seen on the spectrum of the wet sample. The change of the relative intensities of the $\mathrm{C}-\mathrm{O}-\mathrm{C}$ bands indicates conformational changes because these modes are sensitive to dihedral angles.

The 1232 and $1258 \mathrm{~cm}^{-1}$ bands are related to C-O stretching modes of C-O-H groups. The C-H bending modes are attributed to the 1330 and $1360 \mathrm{~cm}^{-1}$ bands. The $1418 \mathrm{~cm}^{-1}$ matches the typical frequency of the symmetric stretching of the $\mathrm{COO}^{-}$group. The corresponding antisymmetric $\mathrm{COO}^{-}$ the band is found at $1600 \mathrm{~cm}^{-1}$. The dried pectin shows a band at $1742 \mathrm{~cm}^{-1}$ due to COOH groups. The band at $1670 \mathrm{~cm}^{-1}$ is related probably to the amide I band. The presence of AuNPs does not affect the infrared spectrum (Figure 2c) significantly.

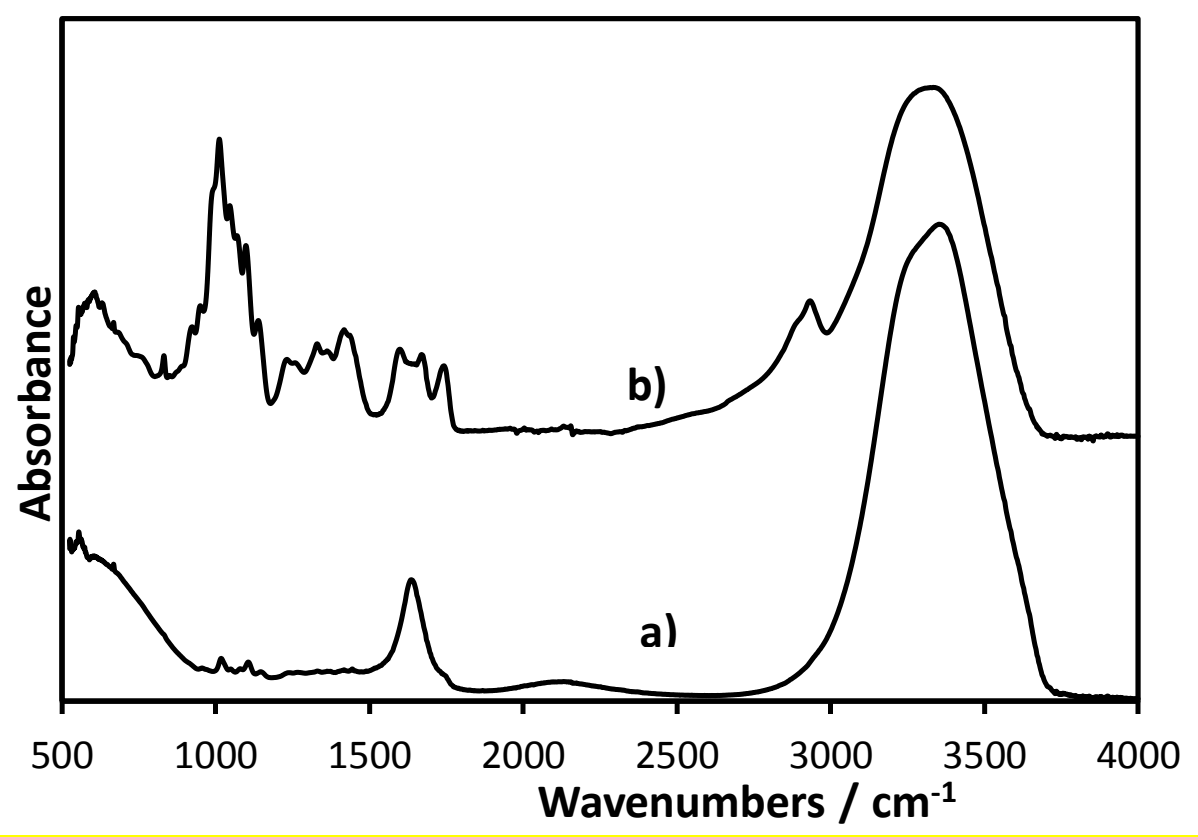

Figure S6. Infrared spectra of the pectin gel (a) and dried pectin (b).

The intense band in the Raman spectrum of pectin (Fig 3a) observed at $854 \mathrm{~cm}^{-1}$ corresponds to C-C and C-C-O motions. The overlapping bands in the $1000-1200 \mathrm{~cm}^{-1}$ range correspond to skeletal $\mathrm{C}-\mathrm{O}$ and $\mathrm{C}-\mathrm{C}$ vibration bands of glycosidic bonds and pyranoid ring. The range between 
1200 and $1400 \mathrm{~cm}^{-1}$ is dominated by the $\mathrm{CH}$ and $\mathrm{OH}$ bending motions. The strong band at 2946 $\mathrm{cm}^{-1}$ is characteristic for the $\mathrm{C}-\mathrm{H}$ stretching modes. Similar bands were observed in Raman spectra of citrus pectins reported by other authors ${ }^{12,13}$. The amidation of the pectin is difficult to discern. Typically the amide III band is the strongest among amide bands in the Raman spectrum. The frequency of the amide III band falls in the $1200-1300 \mathrm{~cm}^{-1}$ range, which overlaps here with the $\mathrm{CH}$ and $\mathrm{OH}$ deformation modes of pectin.

\section{S5 X-ray photoelectron spectroscopy}

In order to identify metallic components and the degree of their reduction in the absence and presence of an additional reductant: $\mathrm{NaBH}_{4}$, XPS spectra of the NMNPs/pectin films were recorded. Deconvolution of HR XPS spectra of Au 4f, Ag 3d, Pt 4f and Pd 3d (Figure S7) reveals the chemical character of $\mathrm{Au}, \mathrm{Ag}, \mathrm{Pt}$ and $\mathrm{Pd}$, respectively, in the pectin matrix (Table $\mathrm{S} 1$ ). The Au 4f spectra are well fitted by two doublet peaks at $\mathrm{BE}$ of the $\mathrm{Au} 4 \mathrm{f}_{7 / 2}$ signals located at $84.0 \mathrm{eV}$ and $85.0 \mathrm{eV}$, corresponding to the metallic state and $\mathrm{Au}^{1+}$, respectively ${ }^{14,15}$. Deconvolution of $\mathrm{Ag} 3 \mathrm{~d}$ and $\mathrm{Pt} 4 \mathrm{f}$ spectra also reveals oxidized forms of both metals $\left(\mathrm{Ag} 3 \mathrm{~d}_{5 / 2}\right.$ at $368.6 \mathrm{eV}$ for $\mathrm{Ag}^{1+}$ and $\mathrm{Pt} 4 \mathrm{f}_{7 / 2}$ at $72.9 \mathrm{eV}$ for $\mathrm{Pt}^{2+}$, respectively) in addition to their metal state $\left(\mathrm{Ag} 3 \mathrm{~d}_{5 / 2}\right.$ at $368.1 \mathrm{eV}$ and $\mathrm{Pt} 4 \mathrm{f}_{7 / 2}$ at $71.2 \mathrm{eV})^{14}$. In turn, Pd $3 \mathrm{~d}$ spectra consist of two doublet peaks at the $\mathrm{Pd} 3 \mathrm{~d}_{5 / 2}$ signals close to 335.8 $\mathrm{eV}$ and $337.6 \mathrm{eV}$, which can be assigned to the metallic state of Pd and PdOx states, respectively ${ }^{14}$. 
$\mathrm{Au} 4 \mathrm{f}$

(a)

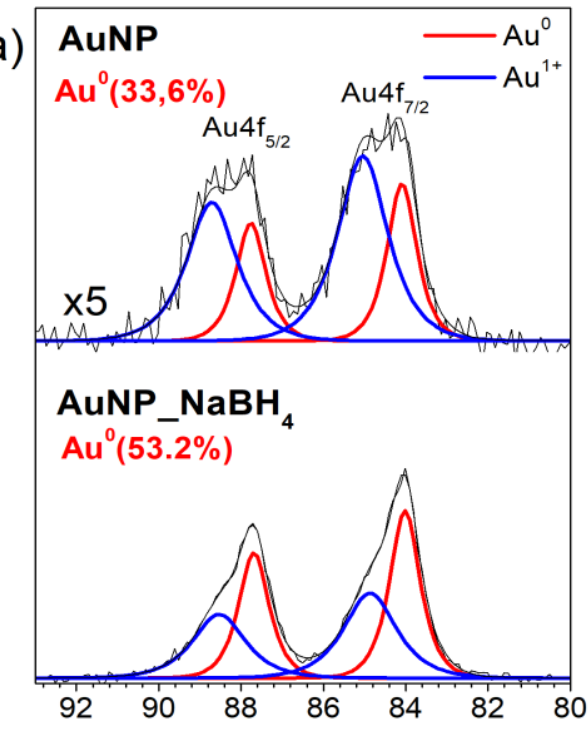

Pt $4 f$

(c)

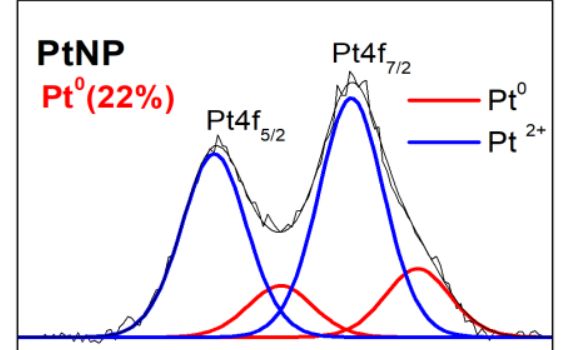

\section{PtNP_NaBH ${ }_{4}$}

$\mathrm{Pt}^{0}(74 \%)$

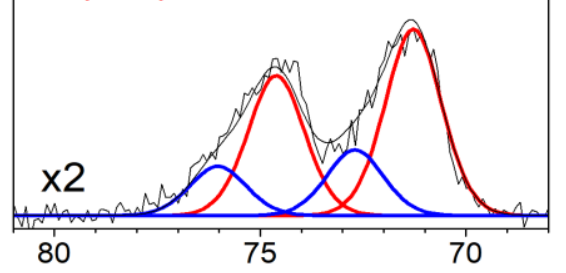

(b)

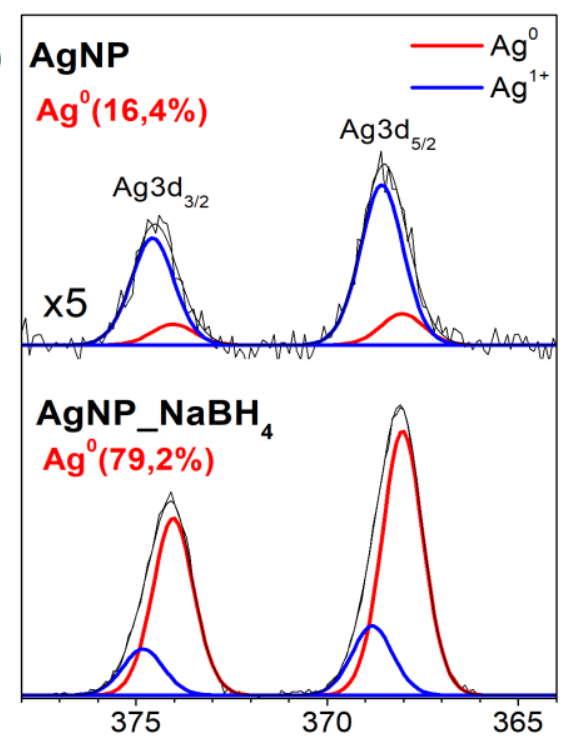

$\operatorname{Pd} 3 d$

(d)

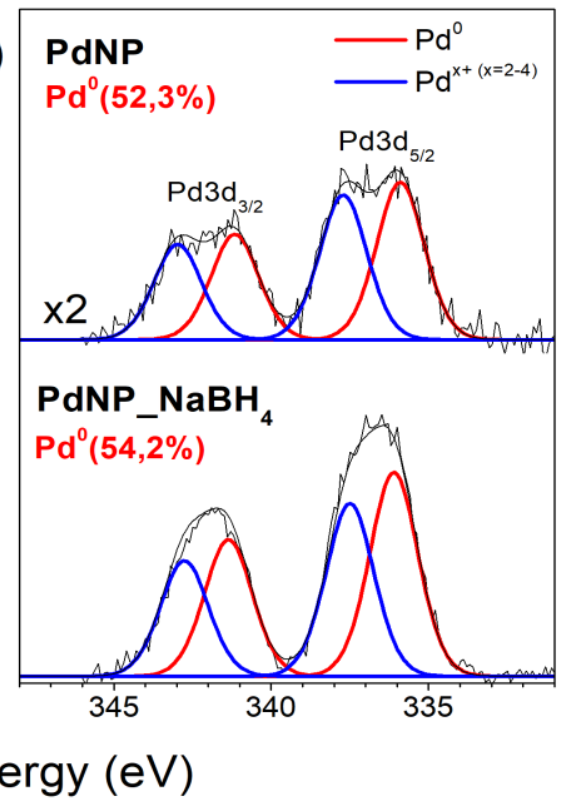

Figure S7. High resolution Au4f, Ag 3d, Pt 4f and Pd 3d XPS spectra of AuNPs/pectin (a), AgNPs/pectin (b), PtNPs/pectin (c) and PdNPs/pectin (d) in the absence and presence of additional reducing agent $\mathrm{NaBH}_{4}$. 
Table S1. Chemical character of $\mathrm{Au}, \mathrm{Ag}, \mathrm{Pd}$ and Pt states in the surface layer of NMNP/pectin films obtained in the absence and presence of $\mathrm{NaBH}_{4}$ composites evaluated by XPS analysis. The $\mathrm{Me} / \mathrm{C}$ atomic concentration ratio for all Me doped NP is presented in a separate column.

\begin{tabular}{|c|c|c|c|}
\hline \multirow[b]{2}{*}{ Gold } & \multicolumn{2}{|c|}{ Noble metal fraction $(\%)$} & \multirow{2}{*}{$\mathrm{Me} / \mathrm{C}$} \\
\hline & $\mathbf{A u}^{0}$ & $\mathbf{A u}^{1+}$ & \\
\hline AuNPs/pectin & 33.6 & 66.4 & 0.0007 \\
\hline AuNPs/pectin_NaBH 4 & 53.2 & 46.8 & 0.0033 \\
\hline Silver & $\operatorname{Ag}^{0}$ & $\operatorname{Ag}^{1+}$ & \\
\hline AgNPs/pectin & 16.4 & 83.6 & 0.0020 \\
\hline AgNPs/pectin_NaBH 4 & 79.2 & 20.8 & 0.0226 \\
\hline Platinum & $\mathbf{P t}^{\mathbf{0}}$ & $\mathbf{P t}^{2+}$ & \\
\hline PtNPs/pectin & 22 & 78 & 0.0053 \\
\hline PtNPs/pectin_NaBH 4 & 74 & 26 & 0.0021 \\
\hline Palladium & $\mathbf{P d}^{\mathbf{0}}$ & $\mathbf{P d}^{\mathbf{X}+(\mathbf{X}=2-4)}$ & \\
\hline PdNPs/pectin & 52.3 & 47.7 & 0.0053 \\
\hline PdNPs/pectin_NaBH ${ }_{4}$ & 54.2 & 45.8 & 0.0133 \\
\hline
\end{tabular}




\section{S6 Atomic force microscopy}
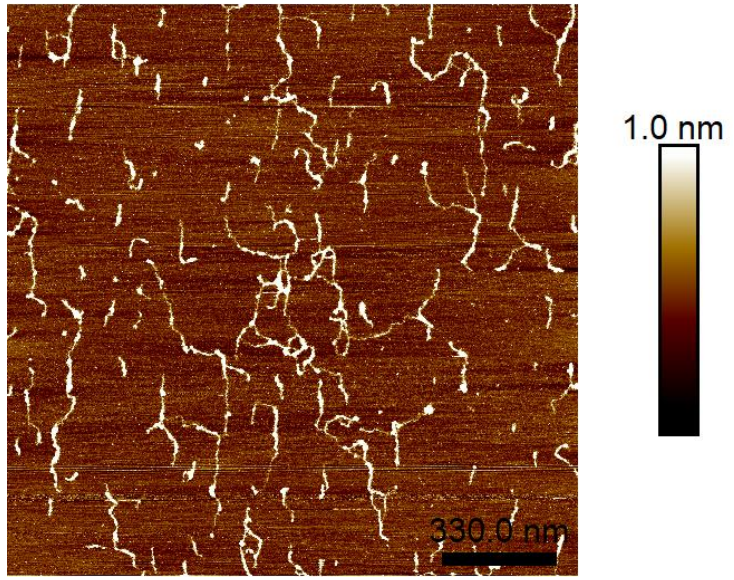

Figure S8. PF QNM AFM image of the height of pectin film deposited on mica.
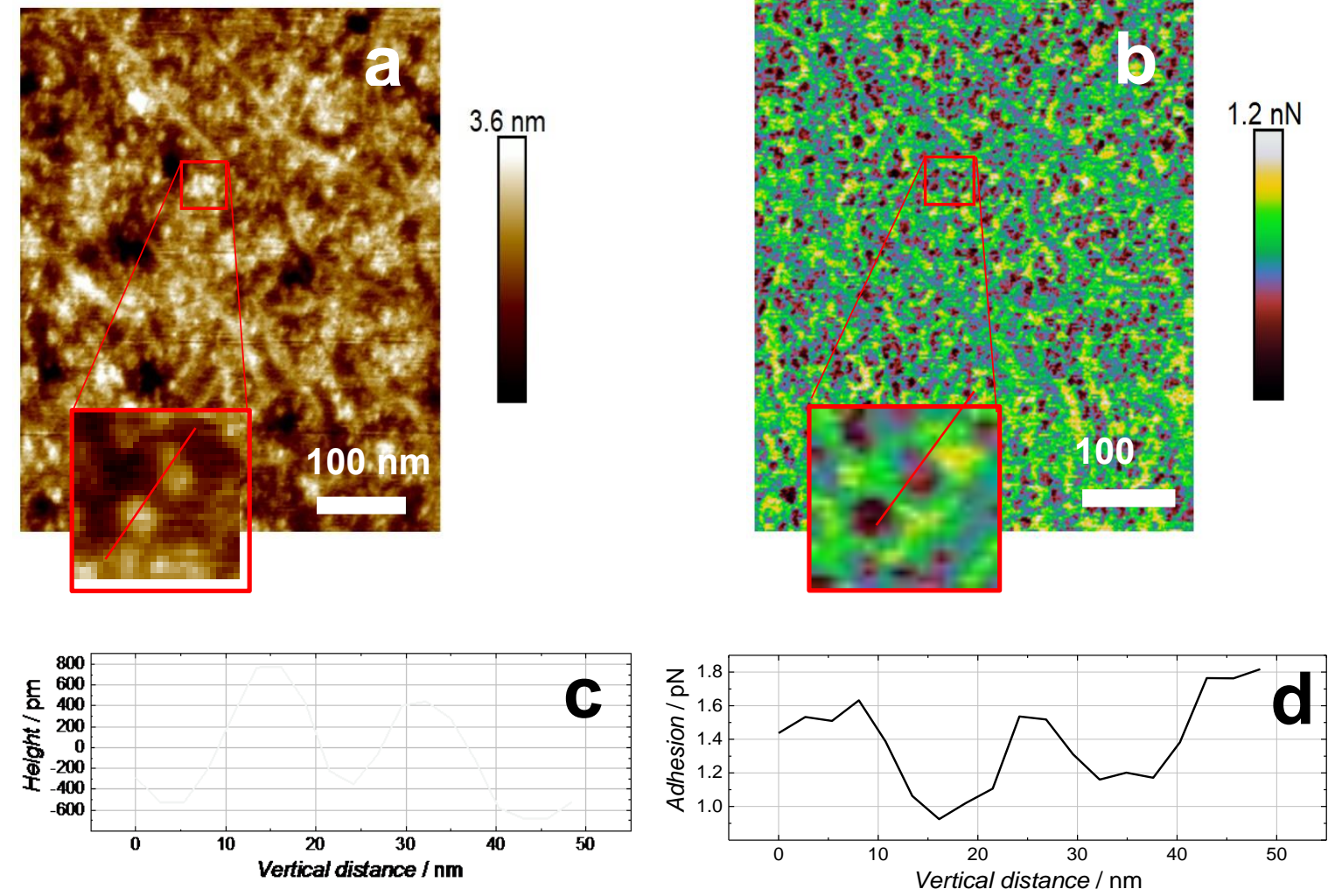

Figure S9. PF QNM AFM image of (a) height and (b) adhesion for the PdNPs/pectin film deposited on mica. Insets show high-resolution images taken for the selected area marked with a square. Cross-section profiles of the height and adhesion are marked as (c) and (d) respectively. The profiles were taken along the red line shown on the images presented in insets. 


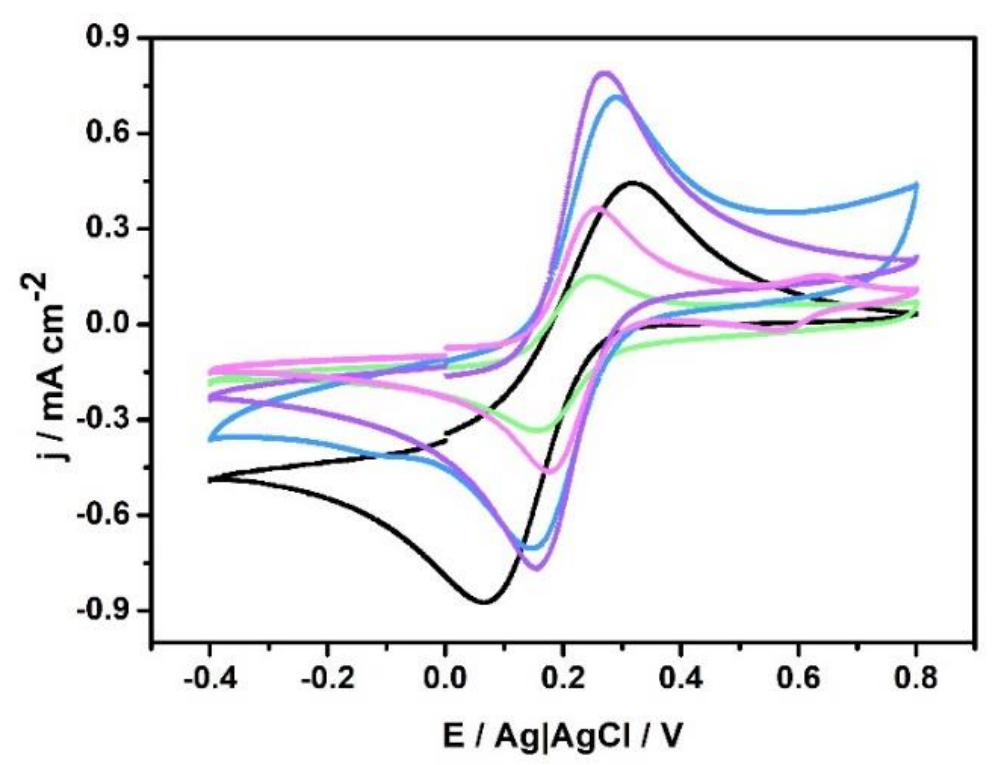

Figure S10. Cyclic voltammograms obtained in $5 \mathrm{mM} \mathrm{K}{ }_{3} \mathrm{Fe}(\mathrm{CN})_{6}$ solution in $0.1 \mathrm{M}$ aqueous PBS at (magenta) PtNPs/pectin, (blue) PdNPs/pectin, (green) AuNP/pectin, (pink) AgNP/pectin and (black) bare GC electrode. Scan rate $0.05 \mathrm{~V} \mathrm{~s}^{-1}$.

The differences in peak currents (Figure S10) may depend on the amount of electroactive material in the film, and results from opposite effects: slower diffusion of the redox probe across the film, electrostatic repulsion of negative charged redox-active anions, pectin carboxylic groups and increase of electrochemically active area as compared to bare GC. 

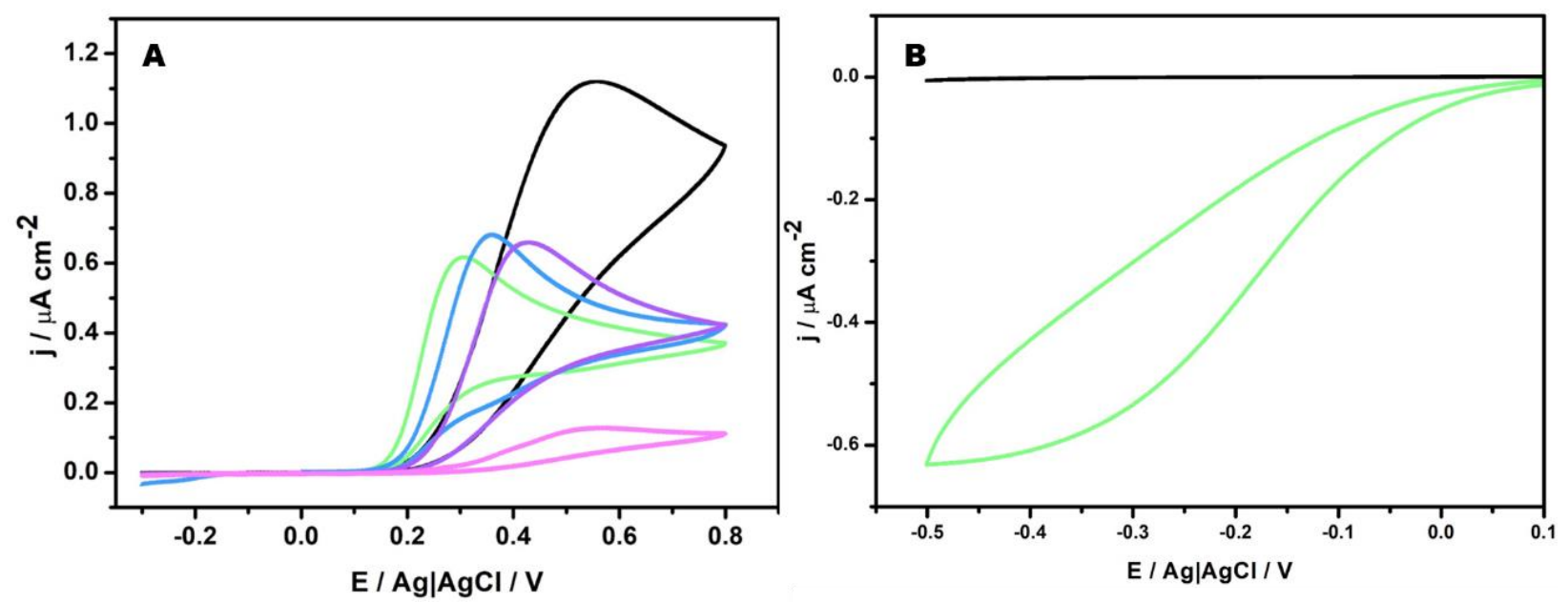

Figure S11. Cyclic voltammograms obtained with (A) PtNPs/pectin (violet), PdNPs/pectin (blue), AuNPs/pectin (green), AgNPs/pectin (magenta) modified and bare GC electrode in $10 \mathrm{mM}$ AA solution in $0.1 \mathrm{M}$ PBS solution (scan rate $0.02 \mathrm{~V} \mathrm{~s}^{-1}$ ) and (B) with AuNPs/pectin (green) modified and bare $\mathrm{GC}$ electrode (black) in $5 \mathrm{mM} \mathrm{H}_{2} \mathrm{O}_{2}$ solution in $0.5 \mathrm{M} \mathrm{H}_{2} \mathrm{SO}_{4}$ (scan rate $0.05 \mathrm{~V}$ $\left.\mathrm{S}^{-1}\right)$

\section{References}

(1) Abramoff, M. D.; Magalhaes, P. J.; Ram, S. J. Image Processing with ImageJ. Biophotonics Int. 2004, 11 (7), 36-41.

(2) Vincent, L.; Soille, P. Watersheds in Digital Spaces: An Efficient Algorithm Based on Immersion Simulations. IEEE Trans. Pattern Anal. Mach. Intell. 1991, 13 (6), 583-598. https://doi.org/10.1109/34.87344.

(3) Roerdink, J.; Meijster, A. The Watershed Transform: Definitions, Algorithms and Parallelization Strategies. Fundam. Informaticae 2000, $41 \quad$ (1-2), 187-228. https://doi.org/10.3233/FI-2000-411207. 
(4) Pittenger, B.; Erina, N.; Su, C. Nanomechanical Analysis of High Performance Materials;

Tiwari, A., Ed.; Solid Mechanics and Its Applications; Springer Netherlands: Dordrecht, 2014; Vol. 203. https://doi.org/10.1007/978-94-007-6919-9.

(5) Maaloum, M.; Sadron-universit, I. C. Measuring the Spring Constant of Atomic Force Microscope Cantilevers : Thermal Fluctuations and Other Methods. Nanotechnology 2002, 13 (1), $33-37$.

(6) Hutter, J. L.; Bechhoefer, J. Calibration of Atomic-Force Microscope Tips. Rev. Sci. Instrum. 1993, 64 (7), 1868-1873. https://doi.org/10.1063/1.1143970.

(7) Toukach, F. V.; Ananikov, V. P. Recent Advances in Computational Predictions of NMR Parameters for the Structure Elucidation of Carbohydrates: Methods and Limitations. Chem. Soc. Rev. 2013, 42 (21), 8376-8415. https://doi.org/10.1039/c3cs60073d.

(8) Cheng, H. N.; Neiss, T. G. Solution NMR Spectroscopy of Food Polysaccharides. Polym. Rev. 2012, 52 (2), 81-114. https://doi.org/10.1080/15583724.2012.668154.

(9) Kpodo, F. M.; Agbenorhevi, J. K.; Alba, K.; Bingham, R. J.; Oduro, I. N.; Morris, G. A.; Kontogiorgos, V. Pectin Isolation and Characterization from Six Okra Genotypes. Food Hydrocoll. 2017, 72, 323-330. https://doi.org/10.1016/j.foodhyd.2017.06.014.

(10) Kamnev, A. A.; Colina, M.; Rodriguez, J.; Ptitchkina, N. M.; Ignatov, V. V. Comparative Spectroscopic Characterization of Di € Erent Pectins and Their Sources. 1998, 12.

(11) Chatjigakis, A. K.; Pappas, C.; Proxenia, N.; Kalantzi, O.; Rodis, P.; Polissiou, M. FT-IR Spectroscopic Determination of the Degree of Esterification of Cell Wall Pectins from Stored 
Peaches and Correlation to Textural Changes. Carbohydr. Polym. 1998, 37, 395-408. https://doi.org/10.1016/s0144-8617(98)00057-5.

(12) Bichara, L. C.; Alvarez, P. E.; Fiori Bimbi, M. V.; Vaca, H.; Gervasi, C.; Brandán, S. A. Structural and Spectroscopic Study of a Pectin Isolated from Citrus Peel by Using FTIR and FTRaman Spectra and DFT Calculations. Infrared Phys. Technol. 2016, 76, 315-327. https://doi.org/10.1016/j.infrared.2016.03.009.

(13) Synytsya, A. Fourier Transform Raman and Infrared Spectroscopy of Pectins. Carbohydr. Polym. 2003, 54 (1), 97-106. https://doi.org/10.1016/S0144-8617(03)00158-9.

(14) Alexander V. Naumkin, Anna Kraut-Vass, Stephen W. Gaarenstroom, C. J. P. NIST X-Ray Photoelectron Spectroscopy Database, National Institute of Standards and Technology, NIST Stand. Ref. Database Number 20. (2000) 20899. NIST X-ray Photoelectron Spectrosc. Database,

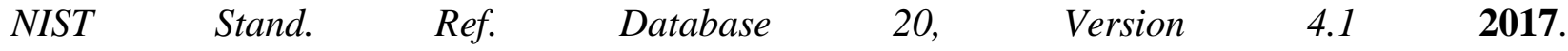
https://doi.org/http://dx.doi.org/10.18434/T4T88K.

(15) Casaletto, M. P.; Longo, A.; Martorana, A.; Prestianni, A.; Venezia, A. M. XPS Study of Supported Gold Catalysts: The Role of $\mathrm{Au} 0$ and $\mathrm{Au}+\delta$ Species as Active Sites. Surf. Interface Anal. 2006, 38 (4), 215-218. https://doi.org/10.1002/sia.2180. 